\title{
Some Thoughts on Strengthening Supply-side Reform of Sports Industry
}

\author{
Qing Li, Qinghan Li \\ Nanchang Institute of Science \& Technology, Nanchang 330108, China
}

\begin{abstract}
:
General secretary Xi Jinping stressed the need to rely on comprehensive deepening reform to promote the structural reform of the supply-side put on an important position, firm confidence in reform, highlighting the problem oriented, strengthen the guidance of the classification, focusing on precision. China's sports industry has developed rapidly in recent years, but there are still some institutional mechanisms. Accelerate the structural supply-side reform of the sports industry, will provide a strong support for the economic development of the new normal consumer demand and stimulate economic growth and sustained power. The sports industry is a sunrise industry, health industry, green industry development, involving many departments, a wide field of sports industry to accelerate the supply- side structural reform, we must proceed from the reality of China's economic and social development, considering the regional differences, reasonable layout, solid foundation, make up the short board, cultivating the industrial multi-subject, taking the characteristic sports industry development road.
\end{abstract}

Keywords: Sports Industry; Supply-side Reform; Demand-Side

\section{Introduction}

The sports industry supply-side reform is a new word recently appeared in the horizon of vocabulary, the so-called "supply-side reforms", is from the supply-side to start production, and through the liberation of productivity, enhance competitiveness and promote economic development. Specifically, it is required to clean up zombie companies, eliminate backward production capacity, the development direction of the lock in the emerging field of innovation, create 
new economic growth points. "Supply-side" and "demand-side" corresponds, at the same time, "supply-side" is the four elements of labor, land, capital and innovation. The sports industry supply-side reforms, is aimed at the current situation and practice of Chinese sports industry, the sports industry in the supply-side as the core, to promote the innovation of mechanism as the starting point, with structural optimization as the focus, to concentrate from the supply side of Chinese promote the sports industry a new round of reform. The main strategy of sports industry supply-side reforms is to reduce the invalid supply of sports industry, increase the effective supply of new media, represented by Internet leveraging innovation dynamic mechanism of the sports industry, the ultimate aim is to revitalize the entire sports industry, so as to achieve leapfrog development.

\section{The origin of sports industry supply-side reform}

The Central government proposed supply-side reform, the main focus is to optimize the economic structure, to avoid the sharp decline in the potential growth rate. In terms of China's current economic situation, the supply-side reform emphasize from the supply side, intended to solve the Chinese consumer demand for upgrading and Chinese manufacturing failed to match with the times. The above mismatch between supply and demand and the contradiction caused by the mismatch, widely exists in the sports industry. The supply and demand in the sports industry to warm the timely response, the industry will be the named "powerless". A member of the CPPCC National Committee, the sports industry expert, director of the State Sports General Administration of sports equipment center Ma Jilong on the inner link of supply-side reform and development of the sports industry said, "the supply-side reform and development of sports industry, sports consumption is a problem in two aspects. Sports service industry in the current sports industry accounted for less than $30 \%$ of the overall, behind the overall level of the industry. The problem is that the effective supply of sports cultural products represented by high level sports is insufficient." Therefore, supply-side reform of sports industry has its urgency.

Sports industry is an important part of modern service industry, it is a new economic growth point and an important carrier of social employment. Sports industry has become the most recognized in the twenty-first century, the most dynamic, with high permeability, cross, pull the sunrise industry, health industry, green industry. However, the proportion of China's sports service industry in the sports industry is less than $30 \%$, far below the level of developed countries in Europe and america.

Many problems exist in the sports industry of our country restrict the further development of sports industry. There is a phenomenon of ineffective supply in the sports industry of our country. There are a lot of fake and shoddy sports goods in the market. Some commodities can meet the needs of consumers in our country in the past years, but they can not meet the requirements of the development stage of the consumers in our country in recent years. Therefore, the 
production capacity is surplus and the supply is invalid. At the same time, we are lack of effective supply in sports industry is very prominent, the domestic sports brand compared to international brands, lack of competitiveness, consumers prefer to buy expensive international brands, also do not want to buy cheap domestic brand products, in other words, some of China's sports brand value-added products are not competitive enough. In addition, the level of China's sports events is not high, the lack of high-quality sporting events and cultural connotations, resulting in the sports event industry's ability to absorb gold and income generating capacity is insufficient.

To solve the bottleneck of the development of China's sports industry, it is necessary to provide more high-end products, to provide a higher level of competition, which is supply-side reform of sports industry to solve those problems.

"Internet plus", which is one of the hot spots in the 2015 national concern, proposed last March to now rising, now has become a universal phenomenon Chinese. "Internet plus" is closely related to the traditional enterprise Internet standards, why traditional enterprises need to expand online market? From the last century at the end of 80 s the Internet began to spread to the Internet Chinese, at the end of 90 s of last century has been gradually popularized in the country, now our life is closely related with the, people increasingly rely on the Internet, home purchase, sale of goods has become homely food. "Internet plus" is the "Internet plus various traditional industries", but this is not a simple combination, but the use of information and communication technology and the Internet platform, so that the Internet and traditional industries depth of integration, to create a new ecological development.

"Internet plus" represents a new form of society, that is to make full use of the Internet to optimize the allocation of resources in the community and integrated function, then innovation will be the integration of the Internet in depth in the fields of economy, society, the whole society to enhance innovation and productivity, to form a more extensive Internet infrastructure and tools the new form of economic development. Some people think that the supply-side reform Internet plus sports is the essence of the sports industry, the ecological operation nature of domestic music as sports is the traditional sports industry.

The reason why the traditional sports industry model is outdated, it is precisely because of the maturity of the Internet technology and applications, as well as the overall popularity of intelligent terminal equipment caused by. The sports industry will be docking with the Internet, a large data set of sports industry development, increase diversity of supply, development and implementation of carrier of sports industry of various kinds, which can not only stimulate new vitality in the sports industry, but also provide a new impetus for innovation and development of the sports industry. 


\section{Development direction of supply-side reform of sports industry}

The modern economy is the experience economy, the experience economy is the enterprise and the consumer exchange, the information and the emotion key set. In other words, the experience exists in the enterprise and consumer contact all the time. Diversified, personalized, accurate service is in line with the requirements of the experience economy, so that consumers feel the whole business is particularly for him. The sports industry supply side structural reforms need to force the system, to consumer demand as the center, innovation driven implementation of the "standard + " strategy for the engine, improve product standards with international standards, and guide the consumer through the "correct" supply, promote industrial restructuring and upgrading.

Chinese consumers have been spending "survival stage", has already begun to consume "development stage" of the new requirements, the requirements on the whole demand is diversified, personalized and accurate, the consumption demand of the sports industry diversification, personalized, precision in turn forced sports supply side structure optimization and industry upgrade, finally meet consumer diversification, personalized, precision of consumer demand.

Since the reform and opening up, China's sports industry has made remarkable achievements, but on the whole, there are many contradictions and practical problems in China's sports industry. One is the effective supply can not well adapt to changes in demand, big but not strong, but not excellent phenomenon did not change significantly, resulting in the structural imbalance of sports industry supply; two is the unreasonable supply structure for sustainable development has brought tremendous pressure. With the change of the overall economic situation at home and abroad, the internal and external environment of sports industry is facing great pressure. Optimize the structure of the sports industry, is to do on the side of the sports supply, according to the market needs to improve the accuracy of the supply, according to the scale of the expansion of the scale of consumption, effective integration of resources to achieve efficient supply.

The relationship between sports industry supply-side reforms must handle the supply side and demand side, adhere to three principles: the reform of sports needs to do sports consumption diversification; sports supply-side reforms should be adapt to the demand side, and actively guide the sports supply; the supply side demand side reform, demand side guide supply-side reforms. Demand side to create consumption, the impact of the market, the market will not be able to grasp bad. The supply side is the only source of economic growth, poor treatment will lead to ineffective supply and effective supply. The relationship between the demand side and the supply side is not good, which will lead to the dislocation of supply and demand.

The first kinetic energy is Internet plus sports, Internet plus sports with the help of the Internet as a tool, the flexible production capacity and demand manufacturer people corresponds, become the key of success or failure of the supply side ". The second kinetic energy is sports social organization, the 
government should decentralization, so that more social organizations to participate in the sports supply side, effectively expanding the sports consumption. The Third kinetic energy is the main body of sports supply diversification, encourage new organizational units or departments to participate in sports supply, the formation of large-scale sports supply and precision of the resultant supply. The Fourth kinetic energy is a new sports business model, encourage enterprises and sports organizations innovation, with more independent intellectual property rights of the product, and ultimately the formation of brand competitiveness, so as to have a place in the international market.

\section{Conclusion}

Supply-side reform of sports industry is required in today's national economic policy era, is the inherent requirement of current development, is an inevitable trend in the "Internet plus" in the larger environment. Supply-side reform of sports industry is rooted in the change of the demand side of sports industry. The key to supply-side reform of sports industry is to improve the accuracy of the supply and expand the scale of supply, and ultimately to achieve efficient supply. Through the docking of emerging technologies such as the Internet, improve the production capacity of the supply side, and in order to promote economic growth, will be able to improve the entrepreneurial ability of the sports industry.

Provides a rare opportunity and power supply side structural reforms for the development of sports industry, to solve the bottleneck problem of the sports industry needs to find a way out from the supply-side reform, solve sports comprehensive deepening of reform and the problems encountered in the need to find countermeasures from the sports industry and sports industry development, to solve the problem of insufficient economic development momentum need to find the highlights from the sports industry. Only the supply side of the sports industry to accelerate the implementation of structural reforms, a good grasp of the sports industry development direction and focus, through policy support to complement the development of the short board, expand the effective supply and service, in order to make the sports industry become an important force in promoting economic and social development.

\section{References:}

[1] Gefei L I, Univ W S. Supply-side Structural Reform and Development of Chinese Sports Industry[J]. Journal of Wuhan Institute of Physical Education, 2016.

[2] Huang Q H. On China Industrial Structural Reform of the Supply Front[J]. China Industrial Economics, 2016.

[3] Zhao P, University J. Supply Side Structural Reform under the New Normal[J]. China Business \& Market, 2016. 
[4] Tian Z H, Yan F U. Survey on Coatings Industry under Supply-side Structural Reform[J]. China Coatings, 2016.

[5]Yang C, Yang X. The Logic behind the Supply-side Reform[J]. Journal of Graduate School of Chinese Academy of Social Sciences, 2016. 